\title{
Correction to: Kinetics of gas production of fodder of Moringa oleifera Lam grown in tropical dry forest areas from Colombia
}

\author{
I. I. García $(i) \cdot$ J. Mora-Delgado $\cdot$ J. Estrada $\cdot$ R. Piñeros
}

Published online: 2 July 2019

(C) Springer Nature B.V. 2019

Correction to: Agroforest Syst

https://doi.org/10.1007/s10457-019-00409-0

The article Kinetics of gas production of fodder of Moringa oleifera Lam grown in tropical dry forest areas from Colombia, written by I. I. García, J. MoraDelgado, J. Estrada, R. Piñeros, was originally published electronically on the publisher's internet portal (currently SpringerLink) on 12 June 2019 with open access.

With the author(s)' decision to step back from Open Choice, the copyright of the article changed on June 2019 to (C) Springer Nature B.V. 2019 and the article is forthwith distributed under the terms of copyright.

The original article has been corrected.
The original article can be found online at https:// doi.org/10.1007/s10457-019-00409-0.

I. I. García $(\bowtie)$ J. Mora-Delgado · R. Piñeros Department of Livestock Production, LivestockAgroforestry Systems Research Group, Universidad del Tolima, Ibague, Colombia

e-mail: igarcia@ut.edu.co

J. Estrada

Department of Production Systems, Biology of Livestock Production Research Group, Universidad de Caldas,

Manizales, Colombia 